\title{
THE PREVALENCE OF METABOLIC SYNDROME AMONG ACTIVE SPORTSMEN/SPORTSWOMEN AND SEDENTARY WORKERS IN THE KUMASI METROPOLIS
}

\author{
${ }^{1}$ W. K. B. A. Owiredu, ${ }^{2}$ N. Amidu, ${ }^{2}$ E. Gockah-Adapoe, ${ }^{1}$ R. K. D. Ephraim \\ ${ }^{I}$ Department of Molecular Medicine, School of Medical Sciences, College of Health Sciences, \\ Kwame Nkrumah University of Science and Technology, Kumasi, Ghana \\ ${ }^{2}$ Department of Medical Laboratory Technology, Faculty of Allied Health Sciences, College of \\ Health Sciences, Kwame Nkrumah University of Science and Technology, Kumasi, Ghana
}

\begin{abstract}
This study sought to establish the prevalence of the metabolic syndrome (MetS) among active sportsmen/sportswomen and sedentary workers in the Kumasi Metropolis using the National Cholesterol Education Program Adult Treatment Panel III (NCEP ATP III), World Health Organization (WHO), and International Diabetes Federation (IDF) criteria. The study was conducted between March and April, 2010. One hundred and eighty six (186) participants were involved with eighty five (85) being active sportsmen/sportswomen as study control and one hundred and one (101) sedentary workers from the Kumasi metropolis as study subjects. The study participants were recruited from a population of young and adult individuals between the ages of 19-82 years. The percentage prevalence of MetS was $1.6 \%, 7.4 \%$ and $14.4 \%$ when the WHO, NCEP-ATP III and IDF criteria respectively were applied on the total population. Generally, the prevalence of MetS was significantly higher among the sedentary group i.e. 3.5\%, 14.0\% and 26.7\% for WHO, NCEP-ATP III and IDF criteria respectively as compared to the active population i.e. $0.0 \%, 2.0 \%$ and $3.9 \%$ for WHO, NCEP-ATP III and IDF criteria respectively. The prevalence of the MetS varied greatly between the active and sedentary subjects depending on the criteria used. Central obesity appears to be the key determinant of the prevalence of the MetS in Ghana. Preventive actions such as exercise, active lifestyles and healthy eating habits have to be implemented to reduce the tendency to obesity and MetS in the Ghanaian populace.
\end{abstract}

Keywords: Metabolic Syndrome; Obesity; Sedentary; Sportsmen/Sportswomen; Ghanaian.

\section{INTRODUCTION}

The metabolic syndrome (MetS) is a group of cardiovascular risk factors characterized by abdominal obesity, central obesity, insulin resistance, atherogenic dyslipidemia, and hypertension (Deedwania and Gupta, 2006). Even though differences exist in the various definitions of the metabolic syndrome; the regular pathophysiology of this syndrome is insulin resistance (Ford, 2004). Abdominal or central obesity remains the major clinical feature of this syndrome. According to Alberti et al. (2006), the criteria for the MetS include five variables namely; abdominal obesity, raised triglycerides, low high density cholesterol (HDL), elevated blood pressure and a history of diabetes mellitus or impaired fasting glucose state. The risk of developing diabetes and car- 


\section{Owiredu et al.}

diovascular disease is increased in people with the metabolic syndrome. Because of the high prevalence and the morbidity and mortality associated with this syndrome, a detailed understanding of its risk factors is central to developing appropriate primary and secondary preventive programmes.

Obesity is an increasingly important public health problem and is considered a major risk factor for diet-related chronic diseases including MetS, type II diabetes, hypertension, stroke and certain forms of cancer (Grundy et al., 2004). The risk of developing the MetS is directly affected by both genetics and life style factors such as diet and exercise patterns. The causes and prevalence will, therefore, vary from population to population based on the individual's life style (Park et al., 2003).

The prevalence of the MetS among the US adult population is approximately $24 \%$ (Ford $e t$ al., 2002). In developing countries such as Ghana there is paucity of data on the prevalence of the MetS among the population. However, with the increasing westernization of Ghanaian lifestyle and eating habits the prevalence of obesity and the metabolic syndrome has been reported to be on the increase. Recent studies conducted in Kumasi by Val-Titty et al. (2008) and Turpin et al. (2008) among diabetic and pregnancy induced hypertensive (PIH) patients put the prevalence of the metabolic syndrome at $55.9 \%$ (NCEP ATP III) for the diabetics; and at $10 \%$ (WHO) and 62\% (NCEP ATP III) for the PIH patients respectively.

Lifestyle changes have been shown to alter the prevalence and severity of MetS, as well as to reduce insulin resistance in adults (Helge, 2002). Among modifications in lifestyle, increase in physical activity plays a significant role (Balkau et al., 2006). Studies by Ford et al. (2002) and Kartzmarzyk et al. (2004) have reported an inverse relationship between physical activity and increased risk of coronary heart disease in a healthy adult population. Physical activity can decrease several risk factors, which include reducing LDL cholesterol and triglyceride levels, raising HDL cholesterol, improving insulin sensitivity, and lowering of blood pressure (Helmrich et al., 1991). The aim of this study, therefore was to establish the prevalence of the metabolic syndrome among active sportsmen/sportswomen and sedentary workers (bank and business executives whose vocations involves sitting for long hours) in the Kumasi Metropolis.

\section{MATERIALS AND METHODS \\ Subjects}

This study was conducted between March and April, 2010. One hundred and eighty six (186) participants were involved with eighty five (85) being active sportsmen/sportswomen as control and one hundred and one (101) sedentary workers from the Kumasi metropolis as participants. The study participants were recruited from a population of young and adult individuals between the ages of 19-82 years. Active sportsmen/sportswomen were individuals who were engaged in any physical activity causing light perspiration or a slight to moderate increase in breathing or heart rate for at least 30 minutes. The participation of the respondents who are all indigenes of Ghana was voluntary and informed consent was obtained from each of them after thorough explanation of what the study entailed. This study was approved by the School of Medical Sciences and KATH Committee on Human Research Publications and Ethics (CHRPE/02/10).

\section{Sample Processing}

Venous blood samples were collected after an overnight fast (12-16 hours) between 7 am and $10 \mathrm{am}$. About $5 \mathrm{ml}$ of venous blood was collected. Four (4) $\mathrm{ml}$ was dispensed into vacutainer $^{\circledR}$ plain tubes and one (1) $\mathrm{ml}$ into fluoride oxalate tubes. After centrifugation at $500 \mathrm{~g}$ for 15 minutes, the serum and plasma were stored at $-80^{\circ} \mathrm{C}$ until assayed. Parameters that were determined include: fasting blood glucose (FBG), total cholesterol (TC), triglycerides (TG) and high density lipoprotein cholesterol (HDL-C). Serum low density lipoprotein cho- 
lesterol (LDL-C) was calculated using the Frederickson-Friedwald's formula according to which LDL-C = TC- TG/2-HDL-C. The methods adopted for the determination of the above parameters were predetermined by the reagent manufacturer - (Fortress Diagnostics Limited, Unit 2C Antrim Technology Park, Antrim BT41 1QS, United Kingdom). Total cholesterol determination was according to the method described by Trinder (1969). Triglycerides determination employed a modified Trinder method.

\begin{abstract}
Anthropometric variables
Anthropometric measurements included height to the nearest centimetre without shoes and weight to the nearest $0.1 \mathrm{~kg}$ in light clothing. Subjects were weighed on a bathroom scale (Zhongshan Camry Electronic Co. Ltd, Guangdong, China) and their height measured with a wall-mounted ruler. Body mass index (BMI) was calculated by dividing weight $(\mathrm{kg})$ by height squared $\left(\mathrm{m}^{2}\right)$. Waist circumference (to the nearest centimeter) was measured with a Gulick II spring-loaded measuring tape (Gay Mills, WI) midway between the inferior angle of the ribs and the suprailiac crest. The hip circumference was measured as the maximal circumference over the buttocks in metres and the waist to hip ratio (WHR) calculated by dividing the waist circumference $(\mathrm{m})$ by the hip circumference $(\mathrm{m})$.
\end{abstract}

\section{Metabolic Syndrome Definitions \\ National Cholesterol Education Program, Adult Treatment Panel III (NCEP ATP III).}

Metabolic syndrome was defined according to the criteria of the National Cholesterol Education Programme, Adult Treatment Panel III (NCEP ATP III) to include individuals with any three or more of the following five components: (1) abdominal obesity-ATP III (waist circumference $>102 \mathrm{~cm}$ for men, or $>$ $88 \mathrm{~cm}$ for women); (2) high $\mathrm{TG} \geq 1.7 \mathrm{mmol} / \mathrm{L}$ (150 mg/dl); (3) low HDL-C : men $<0.9 \mathrm{mmol} /$ $\mathrm{L}(<40 \mathrm{mg} / \mathrm{dl})$ or women $<1.0 \mathrm{mmol} / \mathrm{L}(<50$ $\mathrm{mg} / \mathrm{dl}$ ); and (4) High BP (systolic BP $\geq 130$ $\mathrm{mm} \mathrm{Hg}$ or diastolic $\mathrm{BP} \geq 85 \mathrm{~mm} \mathrm{Hg}$ or treatment of hypertension); and (5) high fasting glucose $\geq 6.1 \mathrm{mmol} / \mathrm{l}$ (NCEP, 2001).

\section{International Diabetes Federation (IDF)}

According to the new definition by the International Diabetes Federation (IDF) (Alberti et al., 2006), metabolic syndrome can be diagnosed if central obesity (waist measurement $>90 \mathrm{~cm}$ for men or $>80 \mathrm{~cm}$ for women) is accompanied by any 2 of the following 4 factors: (1) TG levels of $1.7 \mathrm{mmol} /$ L or greater, (2) an HDL cholesterol lower than $1.03 \mathrm{mmol} / \mathrm{L}$ for men or lower than $1.29 \mathrm{mmol} /$ $\mathrm{L}$ for women, (3) a blood pressure (BP) of $130 / 85 \mathrm{~mm} \mathrm{Hg}$ or greater or treatment of previously diagnosed hypertension, and (4) a fasting blood glucose (FBG) of $5.6 \mathrm{mmol} / \mathrm{L}$ or greater or previously diagnosed type 2 diabetes.

\section{World Health Organization (WHO)}

World Health Organization criteria (Alberti et $a l$. , 2005) required presence of diabetes mellitus, impaired glucose tolerance or insulin resistance and any two of the following: (1) Body mass index (BMI) $\geq 30 \mathrm{~kg} / \mathrm{m}^{2}$ and/or waist-to-hip ratio $>0.90$ (male), $>0.85$ (female), (2) blood pressure $\geq 140 / \geq 90 \mathrm{mmHg}$ or on medication, (3) diabetes $\geq 6.1 \mathrm{mmol} / \mathrm{L}$ or on medication for diabetes, impaired glucose tolerance or insulin resistance, (4) triglyceride $\geq 1.7 \mathrm{mmol} / \mathrm{L}$ and/or HDL-C $<0.91 \mathrm{mmol} / \mathrm{L}$ (male), $<1.01 \mathrm{mmol} / \mathrm{L}$ (female).

\section{Statistical Analysis}

The results are expressed as Means \pm SEM. Unpaired t-test was used to compare mean values of continuous variables and $\chi^{2}$ was used to compare categorical variables. A level of $\mathrm{p}<0.05$ was considered as statistically significant. GraphPad Prism version 5.00 for windows was used for statistical analysis (GraphPad software, San Diego California USA, www.graphpad.com).

\section{RESULTS}

\section{General characteristics of the population}

From this study, the mean age of the sedentary subjects $(45.10 \pm 1.45)$ was similar $(\mathrm{p}=0.1203)$ 
to the mean age of the active control $(42.51 \pm$ 0.90). However, the sedentary subjects had significantly broader waist circumference $(\mathrm{p}=$ $0.0002)$ and higher mean blood pressure (i.e. SBP $(p=0.0107)$ and DBP $(p=0.0001)$ as indicators of blood pressure). Whereas the proportion of sedentary subjects who smoke cigarette and drink alcoholic beverages was similar to the active control, a significantly lower proportion of the sedentary participants had attained high education and a higher proportion of them were married as compared to the active population (Table 1). Biochemical assays indicates that, the mean level of HDL cholesterol, fasting blood sugar and uric acid were signifi- cantly higher among the active population as compared to the sedentary group while mean level of LDL cholesterol was higher among the sedentary group (Table 1).

\section{Prevalence of MetS and its score}

The percentage prevalence of MetS was $1.6 \%$, $7.4 \%$ and $14.4 \%$ using WHO, NCEP-ATP III and IDF criteria respectively for the total population. The prevalence was generally higher among the sedentary group (i.e. 3.5\%, 14.0\% and $26.7 \%$ for WHO, NCEP-ATP III and IDF criteria respectively) as compared to the active population (i.e. $0.0 \%, 2.0 \%$ and $3.9 \%$ for WHO, NCEP-ATP III and IDF criteria respec-

Table 1: General characteristic of the studied population stratified by exercise

\begin{tabular}{lllll}
\hline Parameters & $\begin{array}{l}\text { Total } \\
(\mathbf{n = 1 8 6})\end{array}$ & $\begin{array}{l}\text { Sedentary } \\
(\mathbf{n = 8 5})\end{array}$ & $\begin{array}{l}\text { Active } \\
(\mathbf{n = 1 0 1})\end{array}$ & P value \\
\hline Age $(\mathrm{yrs})$ & $43.56 \pm 1.06$ & $45.10 \pm 1.45$ & $42.51 \pm 0.90$ & 0.1203 \\
Anthropometric parameters & $80.54 \pm 0.81$ & $83.77 \pm 1.26$ & $77.82 \pm 0.97$ & 0.0002 \\
WC (cm) & $0.83 \pm 0.01$ & $0.84 \pm 0.01$ & $0.82 \pm 0.01$ & 0.0715 \\
WHR & $24.82 \pm 0.72$ & $25.86 \pm 0.90$ & $23.94 \pm 1.09$ & 0.1838 \\
BMI (kg/m2) & $132.20 \pm 1.71$ & $136.90 \pm 3.04$ & $128.20 \pm 1.76$ & 0.0107 \\
SBP (mmHg) & $79.18 \pm 1.10$ & $83.74 \pm 1.71$ & $75.33 \pm 1.32$ & 0.0001 \\
DBP (mmHg) & & & & \\
Socio-demographic & parameters & $3 / 86(3.5 \%)$ & $5 / 102(4.9 \%)$ & 0.7288 \\
Smokers & $8 / 188(4.3 \%)$ & $22 / 86(25.6 \%)$ & $39 / 102(38.2 \%)$ & 0.0852 \\
Alcoholics & $61 / 188(32.4 \%)$ & $28 / 86(32.6 \%)$ & $74 / 102(72.5 \%)$ & $<0.0001$ \\
High education & $102 / 188(54.3 \%)$ & $45 / 86(52.3 \%)$ & $18 / 102(17.6 \%)$ & $<0.0001$ \\
Married & $63 / 188(33.5 \%)$ & & & 0.2637 \\
Biochemical assays & & $189.10 \pm 4.70$ & $181.50 \pm 4.84$ & 0.0037 \\
TC (mg/dl) & $185.00 \pm 3.40$ & $83.63 \pm 5.63$ & $89.73 \pm 4.56$ & 0.3960 \\
TG (mg/dl) & $86.94 \pm 3.57$ & $38.99 \pm 1.45$ & $94.89 \pm 3.33$ & $<0.0001$ \\
HDL-C (mg/dl) & $69.32 \pm 2.80$ & $133.40 \pm 4.21$ & $74.30 \pm 4.99$ & $<0.0001$ \\
LDL-c (mg/dl) & $101.30 \pm 3.95$ & $87.34 \pm 1.64$ & $93.38 \pm 1.28$ & 0.0037 \\
FBS (mg/dl) & $90.62 \pm 1.04$ & $7.38 \pm 0.22$ & $8.25 \pm 0.22$ & 0.0061 \\
UA (mg/dl) & $7.85 \pm 0.16$ & & & \\
\hline
\end{tabular}

Continuous data were presented as mean \pm SEM; categorical data are presented as proportion with percentages in parenthesis. Continuous data were compared using unpaired t-test whilst categorical data were compared using Fischer's exact test. 
tively) in Table 2. The prevalence was about 7 times higher among the sedentary population as compared to the active population using NCEPATP III and IDF criteria.

The proportion of individuals without any MetS risk factor (i.e. zero metabolic score) was significantly higher among the active population as compared to the sedentary group using all criteria, whereas the proportion of individuals who are about to cross to the MetS zone (i.e. metabolic score of 2) were more associated with the sedentary population as compared to the active individuals (Table 2). Depending on the criteria applied, there are some individuals who possess three or more MetS risk factors yet they do not have metabolic syndrome. This population though was higher among the seden- tary group compared to the active group, was not significant (Table 2).

As shown in Table 3, using NCEP-ATP III and IDF criteria, the prevalence of abdominal obesity (23.3\% in sedentary), raised blood pressure $(37.2 \%$ in sedentary) and reduced HDL-C (70.9\% in sedentary) were significantly higher compared to the active population (i.e. $2.9 \%$, $14.7 \%$ and $12.7 \%$ for abdominal obesity, raised blood pressure and reduced HDL-C respectively). These contributed to the higher prevalence of the MetS (about 7 times) among the sedentary group compared to the active group using these criteria. However, using the WHO criteria, the contributing factors are central obesity and raised blood pressure (Table 3 ).

Table 2: Prevalence of metabolic syndrome and metabolic score among the population stratified by exercise

\begin{tabular}{lcccc}
\hline Parameters & $\begin{array}{l}\text { Total } \\
(\mathbf{n = 1 8 6})\end{array}$ & $\begin{array}{l}\text { Sedentary } \\
(\mathbf{n = 8 5})\end{array}$ & $\begin{array}{l}\text { Active } \\
(\mathbf{n}=\mathbf{1 0 1})\end{array}$ & P value \\
\hline Prevalence of metabolic syndrome & & & \\
WHO & $3(1.6 \%)$ & $3(3.5 \%)$ & $0(0.0 \%)$ & 0.0939 \\
NCEP-ATP III & $14(7.4 \%)$ & $12(14.0 \%)$ & $2(2.0 \%)$ & 0.002 \\
IDF & $27(14.4 \%)$ & $23(26.7 \%)$ & $4(3.9 \%)$ & $<0.0001$ \\
Prevalence of clustering of one or two or more components of metabolic syndrome & \\
WHO & & & \\
0 & $85(45.2 \%)$ & $22(25.6 \%)$ & $63(61.8 \%)$ & $<0.0001$ \\
1 & $69(36.7 \%)$ & $38(44.2 \%)$ & $31(30.4 \%)$ & 0.0681 \\
2 & $22(11.7 \%)$ & $16(8.1 \%)$ & $6(5.9 \%)$ & 0.0044 \\
$>2$ without MetS & $9(4.8 \%)$ & $7(8.1 \%)$ & $2(2.0 \%)$ & 0.0822 \\
NCEP-ATP III & & & & \\
0 & $75(39.9 \%)$ & $12(14.0 \%)$ & $63(61.8 \%)$ & 0.0001 \\
1 & $76(40.4 \%)$ & $44(51.2 \%)$ & $32(31.4 \%)$ & 0.0073 \\
2 & $23(12.2 \%)$ & $18(20.9 \%)$ & $5(4.9 \%)$ & 0.0013 \\
$>2$ without MetS & $0(0.0 \%)$ & $0(0.0 \%)$ & $0(0.0 \%)$ & \\
IDF & & & & \\
0 & $30(16.0 \%)$ & $6(7.0 \%)$ & $24(23.5 \%)$ & 0.0024 \\
1 & $77(41.0 \%)$ & $31(36.0 \%)$ & $46(45.1 \%)$ & 0.2353 \\
2 & $49(26.1 \%)$ & $25(25.6 \%)$ & $27(26.5 \%)$ & 0.7446 \\
$>2$ without MetS & $5(2.7 \%)$ & $4(4.7 \%)$ & $1(1.0 \%)$ & 0.1805 \\
\hline
\end{tabular}

Data are presented as a proportion with corresponding percentages in parenthesis. The proportions were compared using Fischer's exact test. 
Table 3: Prevalence of the various metabolic syndrome risk factors among the study population classified by exercise

\begin{tabular}{|c|c|c|c|c|}
\hline Parameters & $\begin{array}{l}\text { Total } \\
(\mathrm{n}=186)\end{array}$ & $\begin{array}{l}\text { Sedentary } \\
(\mathbf{n}=\mathbf{8 5})\end{array}$ & $\begin{array}{l}\text { Active } \\
(\mathrm{n}=101)\end{array}$ & $P$ value \\
\hline \multicolumn{5}{|l|}{ NCEP-ATP III } \\
\hline Abdominal Obesity & $23(12.2 \%)$ & $20(23.3 \%)$ & $3(2.9 \%)$ & $<0.0001$ \\
\hline Raised fasting glucose & $15(8.0 \%)$ & $5(5.8 \%)$ & $10(9.8 \%)$ & 0.4205 \\
\hline Raised Triglyceride & $21(11.2 \%)$ & $10(11.6 \%)$ & $11(10.8 \%)$ & 1.0000 \\
\hline Raised blood pressure & $47(25.0 \%)$ & $32(37.2)$ & $15(14.7 \%)$ & 0.0006 \\
\hline Reduced HDL-C & $74(39.4 \%)$ & $61(70.9 \%)$ & $13(12.7 \%)$ & $<0.0001$ \\
\hline $\begin{array}{l}\text { WHO } \\
\text { Central Obesity }\end{array}$ & $45(23.9 \%)$ & $29(33.7 \%)$ & $16(15.7 \%)$ & 0.0057 \\
\hline Raised fasting glucose & $15(8.0 \%)$ & $5(5.8 \%)$ & $10(9.8 \%)$ & 0.4205 \\
\hline Hyperlipidaemia & $6(3.2 \%)$ & $5(5.8 \%)$ & $1(1.0 \%)$ & 0.0949 \\
\hline Raised blood pressure & $31(16.5 \%)$ & $23(26.7 \%)$ & $8(7.8 \%)$ & 0.0007 \\
\hline \multicolumn{5}{|l|}{$I D F$} \\
\hline Abdominal Obesity & $23(12.2 \%)$ & $20(23.3 \%)$ & $3(2.9 \%)$ & $<0.0001$ \\
\hline Raised fasting glucose & $15(8.0 \%)$ & $5(5.8 \%)$ & $10(9.8 \%)$ & 0.4205 \\
\hline Raised Triglyceride & $21(11.2 \%)$ & $10(11.6 \%)$ & $11(10.8 \%)$ & 1.0000 \\
\hline Raised blood pressure & $47(25.0 \%)$ & $32(37.2) \%$ & $15(14.7 \%)$ & 0.0006 \\
\hline Reduced HDL-C & $74(39.4 \%)$ & $61(70.9 \%)$ & $13(12.7 \%)$ & $<0.0001$ \\
\hline
\end{tabular}

The prevalence of BMI overweight and obesity, WHR overweight and obesity, hypertension and dyslipidaemia were significantly higher among the sedentary population as compared to the active group (Table 4). The prevalence were $27.9 \%, 17.4 \%, 29.1 \%$, $27.9 \%, 26.7 \%$, and $5.8 \%$ for BMI overweight and obesity, WHR overweight and obesity,
WHR overweight and obesity, hypertension and dyslipidaemia respectively for the active group (Table 4).

Prevalence of MetS stratified by age As shown in Fig. 1, the prevalence of MetS increased with age using chi square test for trend irrespective of the criteria used. 
Table 4 : Prevalence of obesity, hypertension, diabetics and dyslipidaemia among the population classified by exercise

\begin{tabular}{lllll}
\hline Parameters & $\begin{array}{l}\text { Total } \\
(\mathbf{n = 1 8 6})\end{array}$ & $\begin{array}{l}\text { Sedentary } \\
(\mathbf{n = 8 5})\end{array}$ & $\begin{array}{l}\text { Active } \\
(\mathbf{n = 1 0 1})\end{array}$ & P value \\
\hline $\boldsymbol{B M I}$ & & & & \\
Underweight & $15(8.0 \%)$ & $6(7.0 \%)$ & $9(8.8 \%)$ & 0.7889 \\
Normal & $118(62.8 \%)$ & $41(47.7 \%)$ & $77(75.5 \%)$ & 0.0001 \\
Overweight & $34(18.1 \%)$ & $24(27.9 \%)$ & $10(9.8 \%)$ & 0.0020 \\
Obese & $21(11.2 \%)$ & $115(17.4 \%)$ & $6(15.9 \%)$ & 0.0186 \\
WHR & & & & \\
Normal & $124(66.0 \%)$ & $37(43.0 \%)$ & $87(85.3 \%)$ & $<0001$ \\
Overweight & $37(19.7 \%)$ & $25(29.1 \%)$ & $12(11.8 \%)$ & 0.0033 \\
Obese & $27(14.4 \%)$ & $24(27.9 \%)$ & $3(2.9 \%)$ & $<0.0001$ \\
FBS & & & & 0.4205 \\
Hyperglycemia & $15(8.0 \%)$ & $5(5.8 \%)$ & $10(9.8 \%)$ & 0.4205 \\
Impaired Glucose & $15(8.0 \%)$ & $5(5.8 \%)$ & $10(9.8 \%)$ & $<1.0000$ \\
Diabetes & $0(0.0 \%)$ & $0(0.0 \%)$ & $0(0.0 \%)$ & 0.0007 \\
Hypertension & $31(16.5 \%)$ & $23(26.7 \%)$ & $8(7.8 \%)$ & 0.0188 \\
Dyslipideamia & $5(2.7 \%)$ & $5(5.8 \%)$ & $90(0.0 \%)$ & \\
\hline
\end{tabular}

Four categories of BMI ( $\leq 20,20-24.9,25-29.9$, and $\geq 30 \mathrm{~kg} / \mathrm{m} 2)$ were identified. The categories were selected according to WHO recommendations to define individuals with a healthy weight (BMI 20-25), overweight (BMI 25-29.9) and obese (BMI $\geq 30$ ) [1]. Individuals with a BMI $\leq 20 \mathrm{~kg}$ / $m 2$ were classified as underweight. Men with WHR $<0.90,0.90-0.99$ and $\geq 1.0$ were classified as normal weight, overweight or obese respectively, while women were classified in the same categories on the basis of WHR of $<0.80,0.80-0.84$ and $\geq 0.85$, Hypertension $=$ blood pressure $\geq$ $140 / 90 \mathrm{mmHg}$, Hyperglyceamia = fasting blood sugar $\geq 6.1 \mathrm{mmol} / \mathrm{l}$, Impaired Glucose = fasting blood sugar between 6.1 to $6.9 \mathrm{mmol} / \mathrm{l}$, Diabetes = fasting blood sugar greater or equal to 7.0 $\mathrm{mmol} / \mathrm{l}$ and Dyslipideamia $=T G>150 \mathrm{mg} / \mathrm{dl}$ and $\mathrm{HDL}-\mathrm{C}<40 \mathrm{mg} / \mathrm{dl}$

Using NCEP ATP III criteria, the prevalence significantly $\left(\chi^{2}=17.42 ; \mathrm{p}<0.001\right)$ increased from $0.0 \%(0 / 54)$ among the $19-24$ years group to $1.7 \%(1 / 58)$ among the $25-34$ years group through $12.0 \%(3 / 25)$ among the $35-44$ years group before reaching $19.2 \%(5 / 26)$ in the 45 54 years group and $20.0 \%(5 / 25)$ in the greater or equal to 55 years group. WHO MetS also significantly $\left(\chi^{2}=5.27 ; \mathrm{p}=0.0217\right)$ increased from zero to $7.7 \%(2 / 26)$ in the $45-54$ years group before dropping slightly to $4.0 \%(1 / 25)$ in the 55 years group or older. Likewise, IDF MetS increased from $0.0 \%$ to $5.2 \%(3 / 58)$ in the $25-34$ years group through $20.0 \%(5 / 25)$ in group before dropping slightly to $4.0 \%(1 / 25)$ in the 55 years group or older. Likewise, IDF MetS increased from $0.0 \%$ to $5.2 \%(3 / 58)$ in the 25-34 years group through $20.0 \%(5 / 25)$ in the 35-44 years group before reaching $38.5 \%$ $(10 / 26)$ in the $45-54$ years group and dropped slightly to $36.0 \%(9 / 25)$ in the $\geq 55$ years group (Fig. 1). The age specific distribution of the MetS was generally higher among the female compared to their male counterparts. The highest prevalence of MetS among the men was seen in the 45-54 age group. Using chi-square for trend test, the prevalence of MetS increased with age significantly among the female but not 
the male (Fig. 1). The frequency of occurrence of prevalence of the metabolic syndrome generally increased with age. No individual who is is actively engaged in exercise developed WHO MetS. Using the NCEP ATP III criteria, the age of onset of MetS among active sports men

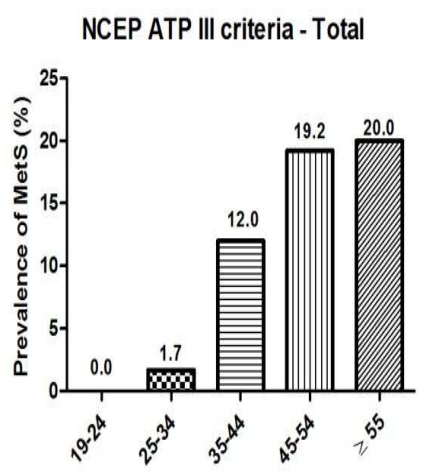

WHO criteria - Total

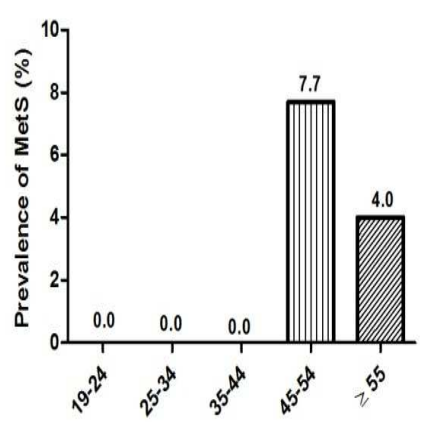

IDF criteria - Total

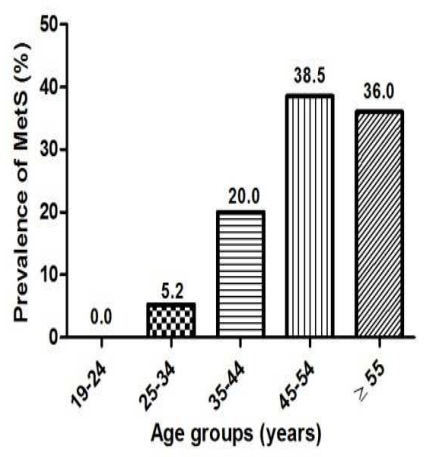

NCEP ATP III criteria - Male

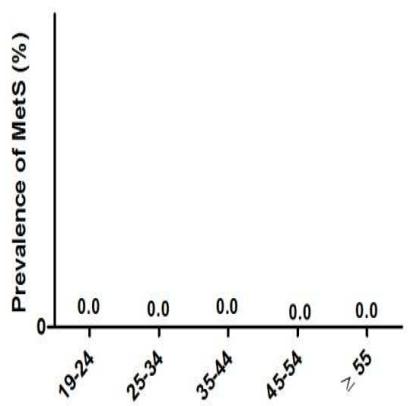

WHO criteria - Male

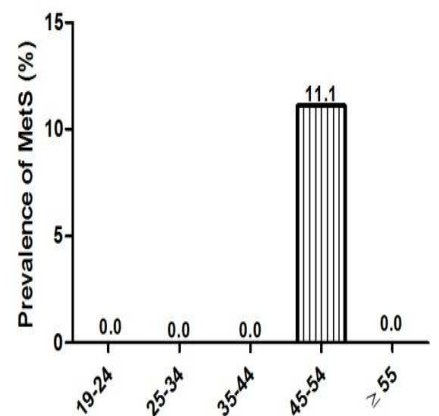

IDF criteria - Male

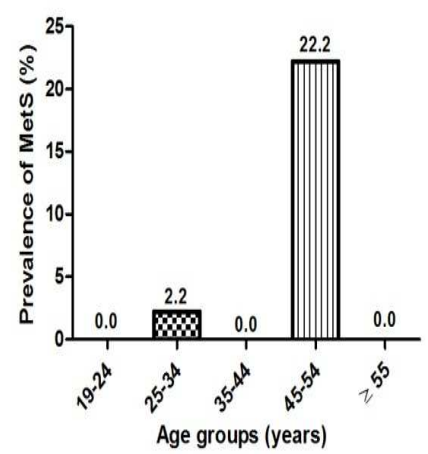

NCEP ATP criteria - Female

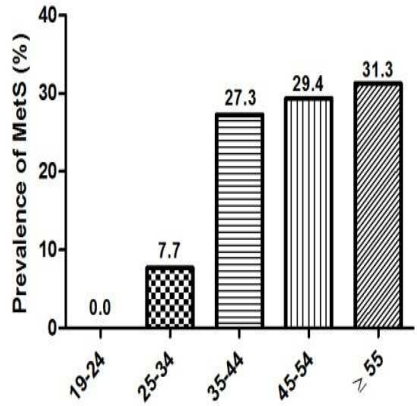

WHO criteria - Female

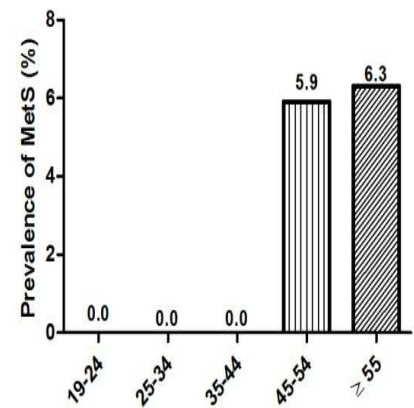

IDF criteria - Female

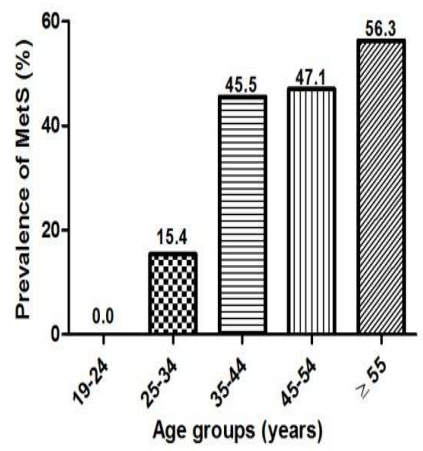

Fig.1: Prevalence of MetS stratified by gender and age 
from this study was 45 - 54 years as compared to the early onset (i.e. 25-34 yearys) among the sedentary subjects. The proportions of subjects with the metabolic syndrome in each age class are shown in Table 5. chelles' (Kelliny et al., 2008) population where the greatest prevalence of MetS was highest at age 45-54 for men. In a Finnish (Ilanne-Parikka et al., 2004) study on MetS, the prevalence of the MetS was found to increase with increasing age in women. Though there is a delayed onset

Table 5 : Prevalence of MetS stratified by lifestyle and age

\begin{tabular}{lccccc}
\hline \multicolumn{5}{c}{ Age groups (years) } \\
\hline \multirow{2}{*}{ Diagnostic Criteria } & $\mathbf{1 9 - 2 4}$ & $\mathbf{2 5 - 3 4}$ & $\mathbf{3 5 - 4 4}$ & $\mathbf{4 5 - 5 4}$ & $\geq \mathbf{5 5}$ \\
& & Sedentary subjects \\
NCEP ATP III & $0 / 3(0.0)$ & $1 / 22(4.5)$ & $3 / 17(17.6)$ & $4 / 23(17.4)$ & $4 / 21(19.0)$ \\
WHO & $0 / 3(0.0)$ & $0 / 22(0.0)$ & $0 / 17(0.0)$ & $2 / 23(8.7)$ & $1 / 21(4.8)$ \\
IDF & $0 / 3(0.0)$ & $2 / 22(9.1)$ & $4 / 17(23.5)$ & $9 / 23(39.1)$ & $8 / 21(38.1)$ \\
& & Active subjects & \\
NCEP ATP III & $0 / 51(0.0)$ & $0 / 36(0.0)$ & $0 / 8(0.0)$ & $1 / 3(33.3)$ & $1 / 4(25.0)$ \\
WHO & $0 / 51(0.0)$ & $0 / 36(0.0)$ & $0 / 8(0.0)$ & $0 / 3(0.0)$ & $0 / 4(0.0)$ \\
IDF & $0 / 51(0.0)$ & $1 / 36(2.8)$ & $1 / 8(12.5)$ & $1 / 3(33.3)$ & $1 / 4(25.0)$ \\
\hline
\end{tabular}

\section{DISCUSSION}

The current study assessed the prevalence of the MetS among sedentary and active populations using the WHO, NCEP ATP III, and the IDF criteria. The prevalence of the MetS, as recorded in this study increased from $1.6 \%$, through $7.4 \%$ to $14.4 \%$ when the WHO, NCEP ATP III, and the IDF criteria respectively were applied. This is consistent with the findings of Fezeu et al., (2007), who conducted similar studies in sub-Saharan Africa. The agedependent prevalence of MetS from this study is irrespective of the criteria used. The impact of age as a risk factor of MetS cannot be overemphasized as this trend has been demonstrated in most study populations around the world (Ford et al., 2002; Ko et al., 2005) .

The age specific prevalence of MetS was higher among the female participants compared to their male counterparts. These findings are in agreement to those documented in a Sey- of MetS among the active subjects from this study as compared to the sedentary subjects, at the age of onset, the active individual had higher rate of MetS using NCEP ATP criteria.

The age of onset of MetS using the IDF criteria was the same for both sedentary and active individual, even though the active group had a slightly lower rate as compared to their counterparts. The reasons for the marked increase in the prevalence of MetS among the active individuals at the age group of $45-54$ years $(33.3 \%)$ and $\geq 55$ years $(25.0 \%)$ is not readily known from this study. However, it is possible that these individuals were engaging in exercise because they had already been clinically diagnosed as having one or more components of MetS and thus had been advised to engage in physical activity to reduce the risk.

The sedentary population studied in this work had broader waist and higher mean blood pres- 
32

sure as observed in the works of Heady et al. (1956) and Ekezie et al.( 2009) respectively. Central obesity is associated with a greater amount of visceral fat than is lower-body obesity, which is associated with more subcutaneous fat. Visceral fat is metabolically active, producing free fatty acids and inflammatory cytokines that drain directly into the liver via the portal circulation (Johnson and Weinstock, 2006). Fat deposits in the liver are associated with overproduction of very-low-density lipoprotein, predisposing the patient to atherogenic dyslipidemia (elevated triglycerides, low HDL cholesterol level, and small dense low-density lipoprotein [LDL] cholesterol particles). Although LDL cholesterol levels may not be elevated, the number of particles may be increased, and the small dense particles more readily enter the arterial wall and are oxidized, leading to atherosclerosis (Johnson and Weinstock, 2006; Koh et al., 2008).

Furthermore, various studies have suggested the modulating effect of exercise on blood pressure (BP); the observation in all the groups is that $\mathrm{BP}$ tends to reduce in mean value as the level of physical activity increases and this supports the report that overall exercise capacity has a very strong association with cardiac events and all-cause mortality in patients with known or suspected coronary artery disease (Morris et al., 1991; Perry et al., 1994).

Byberg et al. (2001) indicated that physically active people had increased HDL cholesterol and decreased fasting glucose. This observation, however, is partially consistent with the findings of the current study where fasting blood glucose levels were increased among the active group in this study. Exercise results in the muscles requiring more glucose to supply adequate energy. In response the liver increases the amount of glucose it releases into the bloodstream. Glucose requires insulin in order to be metabolized by the muscles, thus inadequate insulin may result in elevated blood glucose soon after exercise. Basically, stimulated by the increased glucose demand from exercising muscles, the body increases the secretion of glucose into the bloodstream. The higher mean LDL cholesterol observed in the sedentary group however, is consistent with the findings of other studies (Kronenberg et al., 2000).

The association between sedentary lifestyle and MetS has been reported by previous studies (Ford, 2004; Dalacorte et al., 2009). This study identified an association between sedentary lifestyle and two definitions of MetS: that of the ATP-III (NCEP, 2001) and the IDF (Zimmet et al., 2005). A high prevalence of MetS was recorded in the sedentary population compared to the active population. This observation is consistent with findings made elsewhere (Tudor-Locke and Myers, 2001) which concluded that whichever concepts of sedentary lifestyle and MetS are used, MetS is less frequent among active individuals. However, prevalence of MetS in sedentary individuals is greater if the IDF definition is applied; this is expected since it defines abdominal obesity in terms of a smaller abdominal circumference.

Byberg et al., (2001) also found in a 20 year follow-up of men aged 50 years that those who increased their physical activity (determined through self-reports) had lower BMI, reduced plasma triglycerides, increased HDL cholesterol, decreased fasting glucose, and decreased proinsulin levels. Taken together, the results of the present cross-sectional study and those of previous investigations indicate that physically active men have a lower prevalence of MetS and component risk factors in comparison with physically inactive men.

A study using the NCEP ATP III criteria noted that physical activity has protective effects on the metabolic syndrome through improvements in plasma lipid concentrations, particularly through increases in HDL cholesterol concentrations (Leon and Sanchez, 2001), decreases in triglyceride concentrations (Fahlman et al., 2002) or both (Kraus et al., 2002). In addition, physical activity is associated with lowered blood pressure, improved glucose tolerance 
(Arciero et al., 1999), insulin sensitivity (Irwin et al., 2000), and lowered risk of type 2 diabetes (Hu et al., 2001). Furthermore, using the NCEP-ATP III and IDF criteria, it was observed in this study that the active participants had a significantly lower prevalence of abdominal obesity, raised blood pressure and reduced HDL-C but not triglyceride as compared to the sedentary. This buttresses the fact that physical activity is associated with reduced risk of having the metabolic syndrome (Katzmarzyk et al., 2003). However, using the WHO criteria central obesity and raised blood pressure are the main contributing factors of MetS in the sedentary group.

The present study showed that the prevalence of BMI overweight and obesity, WHR overweight and obesity, hypertension and dyslipidaemia were significantly higher among the sedentary population as compared to the active group. This finding is to a large extent in agreement with the studies of Greenfield et al. (2003) except for dyslipidaemia. Other studies have shown that weight reduction by aerobic exercise significantly reduced blood pressure and improved lipid profile in hypertensive MetS patients (Christ et al., 2004). Furthermore, Ekezie et al. ( 2009) noted that those who regularly exercised have lower values of adiposity measures and blood pressure while those who never exercised, equivalent to the sedentary workers; in most cases have significantly high levels of adiposity and elevated blood pressure.

Uric acid has been identified as one of the biologically important antioxidants for training athletes or exercising persons. Uric acid scavenges organic and inorganic oxygen radicals and can bind iron and copper ions as well as moderate the catalysis of free radical reactions (Halliwell, 1994). Uric acid levels have been reported to increase after exercise in humans (Aslan et al., 1998), and also in experimental animals compared to sedentary controls (Kelle et al., 1999).
These observations have been confirmed in this study where the serum uric acid levels in the active participants were significantly higher compared to the sedentary controls.

\section{Conclusion}

This study has demonstrated the complication associated with the application of diagnostic tools developed in one population to a different population. The three MetS definitions have generated different sets of prevalence values, not only as a consequence of the real burden of the MetS in this population, probably but also because of the varied components in each definition and cutoff levels used. The prevalence of individual risk factors and the trends in these prevalence values are indicators of the burgeoning epidemic of the MetS and its subsequent consequences in Sub-Saharan Africa. The trends in this occurrence have to be monitored in future studies, and specific cut-off points, at least for central obesity, need to be defined for the Ghanaian population. Preventive actions such as exercises and active lifestyles have to be implemented to reduce the impending impact of the MetS in this population.

\section{References}

Alberti, K. G., Zimmet, P. and Shaw, J. (2005).The metabolic syndrome--a new world wide definition. Lancet 366: 1059 . 1062.

Alberti , K. G., Zimmet, P. and Shaw, J. (2006) Metabolic syndrome --a new world-wide definition. A Consensus Statement from the International Diabetes Federation. Diabet Med 23: 469-480.

Arciero, P. J., Vukovich, M. D., Holloszy, J. O., Racette, S. B. and Kohrt, W. M. (1999). Comparison of short-term diet and exercise on insulin action in individu als with abnormal glucose tolerance. $J$ Appl Physiol 86:930-1935.

Aslan, R., Sekeroglu, M., Tarakioglu, M., Bayi roglu, F and Meral, I. (1998). The 
effect of acute regular exercise on antioxidant tissue damage markers and membrane peroxidation of erythrocytes in sedentary students. Tr. J. Medical. Sci, 411-414

Balkau, B., Vierron, E., Vernay, M., Born, C., Arondel, D., Petrella, A. and Ducimetiere, P. (2006). The impact of 3-year changes in lifestyle habits on metabolic syndrome parameters: the D.E.S.I.R study. Eur J Cardiovasc Prev Rehabil 13: 334-340.

Byberg, L., Zethelius, B., McKeigue, P. M. and Lithell, H. O. (2001). Changes in physical activity are associated with changes in metabolic cardiovascular risk factors. Diabetologia 44: 2134-2139.

Christ, M., Iannello, C., Iannello, P.G. And Grimm, W. (2004). Effects of a weight reduction program with and without aerobic exercise in the metabolic syndrome. Int J Cardiol 97: 115-122.

Dalacorte, R. R., Reichert, C. L. and Vieira, J. L. (2009). Metabolic syndrome and physical activity in southern Brazilian community-dwelling elders: a population based, cross-sectional study. BMC Public Health 9, 25.

Deedwania, P. C. and Gupta, R. (2006). Management issues in the metabolic syndrome. J Assoc Physicians India 54: 797 810 .

Ekezie, J., Adebisi, S. S. and Danborno, B. (2009). The Effect of Marital Status and Self-Reported Physical Exercise on the Adiposity and Blood Pressure of the Igbos of Nigeria. Internet Journal of Medical Update 4.

Fahlman, M. M., Boardley, D., Lambert, C. P. and Flynn, M. G. (2002). Effects of endurance training and resistance training on plasma lipoprotein profiles in elderly women. J Gerontol A Biol Sci MedSci 57: B54-60

Fezeu, L., Balkau, B., Kengne, A. P., Sobngwi, E. and Mbanya, J. C. (2007). Metabolic syndrome in a sub-Saharan African setting: central obesity may be the the key determinant. Atherosclerosis 193: 70-76.

Ford, E.S. (2004). Prevalence of the metabolic syndrome in US populations. Endocrinol Metab Clin North Am 33:333-350.

Ford, E. S., Giles, W.H. and Dietz, W. H. (2002). Prevalence of the metabolic syndrome among US adults: findings from the third National Health and Nutrition Examination Survey. JAMA 287: 356359.

Greenfield, J. R., Samaras, K., Campbell, L.V., Jenkins, A. B., Kelly, P. J., Spector, T. D. and Hayward, C. S. (2003). Physical activity reduces genetic susceptibility to increased central systolic pressure augmentation: a study of female twins. $J \mathrm{Am}$ Coll Cardiol 42: 264-270.

Grundy, S. M., Brewer, H. B., Jr., Cleeman, J. I., Smith, S. C., Jr. and Lenfant, C. (2004). Definition of metabolic syndrome: Report of the National Heart, Lung, and Blood Institute/American Heart Association conference on scientific issues related to definition. Circulation 109: 433-438.

Halliwell, B. (1994). Free radicals and antioxidants: a personal view. Nutr Rev 52, 253265. epidemiology of uniforms. Lancet 271: $569-570$

Heady, J.A., Morris, J.N. and Raffle, P.A. (1956). Physique of London busmen; 
epidemiology of uniforms. Lancet 271, 569-570

Helge, J. (2002). Prolonged adaptation to fatrich diet and training; effects on body fat stores and insulin resistance in man. Intern J Obes 26: 1118-1124.

Helmrich, S. P., Ragland, D. R., Leung, R. W. and Paffenbarger, R. S., Jr. (1991). Physical activity and reduced occurrence of non-insulin-dependent diabetes mellitus. N Engl J Med 325: 147-152.

Hu, F. B., Leitzmann, M. F., Stampfer, M. J., Colditz, G. A., Willett, W. C. and Rimm, E. B. (2001). Physical activity and television watching in relation to risk for type 2 diabetes mellitus in men. Arch Intern Med 161, 1542-1548 risk for type 2 diabetes mellitus in men. Arch Intern Med 161: 1542-1548.

Ilanne-Parikka, P., Eriksson, J. G., Lindstrom, J., Hamalainen, H., KeinanenKiukaanniemi, S., Laakso, M., Louheranta, A., Mannelin, M., Rastas, M., Salminen, V., Aunola, S., Sundvall, J., Valle, T., Lahtela, J., Uusitupa, M. And Tuomilehto, J. (2004). Prevalence of the metabolic syndrome and its components: findings from a Finnish general population sample and the Diabetes Prevention Study cohort. Diabetes Care 27:21352140.

Irwin, M. L., Mayer-Davis, E. J., Addy, C. L., Pate, R. R., Durstine, J. L., Stolarczyk, L. M. and Ainsworth, B. E. (2000). Moderate-intensity physical activity and fasting insulin levels in women: the CrossCultural Activity Participation Study. Diabetes Care 23: 449-454.

Johnson, L. W. and Weinstock, R. S. (2006). The metabolic syndrome: concepts and controversy. Mayo Clin Proc 81:
Prevalence of Metabolic Syndrome...

1615-1620.

Katzmarzyk, P. T., Church, T. S. and Blair, S. N. (2004). Cardiorespiratory fitness at tenuates the effects of the metabolic syndrome on all-cause and cardiovascular disease mortality in men. Arch Intern Med 164: 1092-1097.

Katzmarzyk, P. T., Leon, A. S., Wilmore, J. H., Skinner, J. S., Rao, D. C., Rankinen, T. and Bouchard, C. (2003). Targeting the metabolic syndrome with exercise: evi dence from the HERITAGE Family Study. Med Sci Sports Exerc 35: 17031709

Kelle, M., Diken, H., Sermet, A., Atmaca, M. and Tumer, C. (1999). Effect of exercise on blood antioxidant status and erythrocyte lipid peroxidation: Role of Dietary Supplementary of vitamin E. $\mathrm{Tr}$. J. Med. Sci 29: 95-100.

Kelliny ,C., William, J., Riesen, W., Paccaud, F. and Bovet, P. (2008). Metabolic syndrome according to different definitions in a rapidly developing country of the African region. Cardiovasc Diabetol 7 , 27.

Ko, G. T., Cockram, C. S., Chow, C. C., Yeung, V., Chan, W. B., So, W.Y., Chan, N. N. and Chan, J. C. (2005). High prevalence of metabolic syndrome in Hong Kong Chinese--comparison of three diagnostic criteria. Diabetes Res Clin Pract 69: 160-168.

Koh, K. K., Quon, M. J., Rosenson, R. S., Chung, W. J. and Han, S. H. (2008). Vascular and metabolic effects of treat ment of combined hyperlipidemia: focus on statins and fibrates. Int $J$ Cardiol 124:149-159.

Kraus, W. E., Houmard, J. A., Duscha, B. D., 
Knetzger, K. J., Wharton, M. B., McCartney, J. S., Bales, C. W.,

Henes ,S., Samsa, G. P., Otvos, J. D., Kulkarni, K. R. and Slentz, C. A. (2002). Effects of the amount and intensity of exercise on plasma lipoproteins. $N$ Engl J Med 347:1483-1492.

Kronenberg, F., Pereira, M. and Schmitz, M., et al. (2000). Influence of leisure time physical activity and television watching on atherosclerosis risk factors in the NHLBI Family Heart Study. Atherosclerosis. 153: 433- 443.

Leon, A. S. and Sanchez, O. A. (2001). Response of blood lipids to exercise training alone or combined with dietary interven tion. Med Sci Sports Exerc 33, S502-515; discussion S528-509.

Morris, C. K., Ueshima, K., Kawaguchi, T., Hideg, A. and Froelicher, V. F. (1991). The prognostic value of exercise capacity: a review of the literature. Am Heart J $122,: 1423-1431$.

NCEP (2001). Executive Summary of the Third Report of The National Cholesterol Education Program (NCEP) Expert Panel on Detection, Evaluation, And Treatment of High Blood Cholesterol In Adults (Adult Treatment Panel III). JAMA 285:2486-2497.

Park, Y. W., Zhu, S., Palaniappan, L., Heshka, S., Carnethon, M. R. and Heymsfield, S. B. (2003). The metabolic syndrome: prevalence and associated risk factor findings in the US population from the Third National Health and Nutrition Examination Survey, 1988-1994. Arch Intern Med 163: 427-436.
Perry, I. J., Whincup, P. H. and Shaper, A. G. (1994). Environmental factors in the development of essential hypertension. Br Med Bull 50: 246-259.

Trinder, P. (1969). Determination of blood glucose using an oxidase peroxidase system with a non- carcinogenic chromogen J Clin Pathol 22 : 158-161.

Tudor-Locke, C. E. and Myers, A. M. (2001). Challenges and opportunities for measure ing physical activity in sedentary adults. Sports Med 31:91-100.

Turpin, C. A., Ahenkorah, L., Owiredu W.K.B.A., Laing E.F and Amidu. N. (2008). "The Prevalence of the Metabolic Syndrome Among Ghanaian PregnancyInduced Hypertensive Patients Using the World Health Organisation and the National Cholesterol Education Program III Criteria". Journal of Medical Sciences $8: 443-451$

Val-Titty, F. K., Owiredu, W. K. B. A. And Agyei-Frempong, M. T. (2008). Prevalence of Metabolic Syndrome and its Individual Components among Diabetic Patients in Ghana. Journal of Biological Sciences 8: 1057-1061.

Zimmet, P., KG, M. M. A. and Serrano Rios, M. (2005). [A new international diabetes federation worldwide definition of the metabolic syndrome: the rationale and the results]. Rev Esp Cardiol 58: 13711376. 